\title{
Impact of the hyperchloremic component of metabolic acidosis on the patient's hydration status and the treatment of diabetic ketoacidosis
}

\author{
Ismael Toledo, M.D. ${ }^{a}$, Raquel Wainsztein, M.D. ${ }^{a}$, Carla Mannucci, M.D. ${ }^{b}$, \\ Mabel Ferraro, M.D. ${ }^{b}$, Juan Ferreira, M.D. ${ }^{c}$ and Alejandro Balestracci, M.D.
}

\begin{abstract}
Introduction. Diabetic ketoacidosis (DKA) is characterized by metabolic acidosis (MA) with a high anion gap (AG), although, occasionally, it can present with hyperchloremia. It has been postulated that the early presence of hyperchloremia could reflect a better hydration status; however, its prevalence and impact on DKA treatment remain unknown.

Objectives. To determine the prevalence of the hyperchloremic component in MA prior to treatment and to assess whether it is associated with a better hydration status and a shorter recovery time from DKA compared to patients with high AG only.
\end{abstract}

Patients and Methods. Patients hospitalized with DKA (between January 2014 and June 2016) were grouped according to whether they were admitted with MA with high AG only. or with hyperchloremia, and clinical and laboratory outcome measures and response to treatment were compared.

a. Department of Nephrology.

b. Department of Nutrition and Diabetes.

c. Committee of Teaching and Research.

Hospital General de Niños Pedro de Elizalde, Autonomous City of Buenos Aires, Argentina.

E-mail address:

Ismael Toledo, M.D.: maetoledo77@hotmail. com

\section{Funding:}

This study was conducted in the context of a research fellowship granted to Dr. Ismael Toledo by the Department of Pediatrics of the School of Medicine, Universidad de Buenos Aires.

\section{Conflict of interest:}

None.

\section{INTRODUCTION}

Diabetic ketoacidosis (DKA) is a severe complication of type 1 diabetes mellitus (DM). In our country, it is the most frequent form of presentation of the disease in children $(40 \%)$ and the leading cause of death (60-90\%), which, in most cases, is due to associated cerebral edema. ${ }^{1,2}$ A cardinal sign that characterizes this condition is metabolic acidosis (MA) with a high anion gap (AG) due to the excessive production and retention of organic acids or ketoacids ( $\beta$-hydroxybutyrate and acetoacetate), which titer plasma bicarbonate decreasing its concentration. ${ }^{3}$ During treatment, insulin administration promotes the use of ketonic acids with bicarbonate regeneration, and intravenous fluid administration decreases lactic acid output by improving muscle aerobic metabolism. ${ }^{4}$

However, when urinary output increases, renal excretion of ketoacid anions, which were a source of bicarbonate for the action of insulin, raises. Additionally, considering that electrolyte replacement is mostly accomplished with an anion chloride, during its course it might develop a component of hyperchloremic acidosis. ${ }^{4,5}$ Notably, in some patients who have maintained a better hydration status and consequently a greater excretion of ketoacids, this situation might be present since admission. ${ }^{6}$ Besides, the loss of bicarbonate in urine (acute tubular necrosis) or stools (acute gastroenteritis) can contribute to hyperchloremic MA, leading to an increase in chloremia so that electroneutrality is maintained..$^{6,7}$ 
Therefore, given that the hyperchloremic component of DKA prior to the start of treatment might reflect a better hydration status, its presence at the time of diagnosis could be expected to result in a better treatment response; however, as far as we know, no studies have been conducted to evaluate this speculation. The objectives of this study were the following: (1) to determine the prevalence of MA with a hyperchloremic component prior to the start of treatment and (2) to evaluate if this metabolic pattern was associated with a better hydration status and a shorter recovery time from DKA compared to patients with high AG metabolic acidosis.

\section{POPULATION, MATERIAL AND METHODS Patients}

A cross-sectional and observational study was conducted, with prospective data collection of patients younger than 18 years old with DKA (either as the first manifestation, or with a known diagnosis) hospitalized at Hospital General de Niños Pedro de Elizalde between January 1, 2014 and June 30, 2016. Patients with previous chronic kidney disease (including diabetic nephropathy), those who had started treatment for this complication in other healthcare centers before being referred to our hospital, and those with sepsis or multiple organ failure were excluded.

\section{Methods}

All patients enrolled in the study were treated as per our hospital's DKA treatment guidelines, ${ }^{3}$ which describe the changes to be made depending on the different clinical and laboratory findings during the course of the disease. This allowed for consistency regarding the treatment of a condition that requires a dynamic approach. In summary, patients in shock or with a $\mathrm{pH}<7.20$ were administered $20 \mathrm{ml} / \mathrm{kg}$ of saline solution and those with a $\mathrm{pH}<7.0$ received $10 \mathrm{ml} / \mathrm{kg}$ of sodium bicarbonate $(1 / 6$ molar $)+10 \mathrm{ml} /$ $\mathrm{kg}$ of saline solution. During the first 24 hours, patients were hydrated with $4000 \mathrm{ml} / \mathrm{m}^{2}$, infused in two stages, the first half within the first 6 hours (volume: $2000 \mathrm{ml} / \mathrm{m}^{2}$; sodium chloride: $70 \mathrm{mEq} / \mathrm{L}$; potassium chloride: $30 \mathrm{mEq} / \mathrm{L}$; glucose flow: $3.5 \mathrm{mg} / \mathrm{kg} / \mathrm{min}$ ) and the other half during the remaining 18 hours (volume: $2000 \mathrm{ml}$ / $\mathrm{m}^{2}$; sodium chloride: $70 \mathrm{mEq} / \mathrm{L}$; potassium chloride: $40 \mathrm{mEq} / \mathrm{L}$; glucose flow: $3.25 \mathrm{mg} / \mathrm{kg}$ / $\mathrm{min})$. At the same time, regular subcutaneous insulin was administered at an early stage $(0.1$
$\mathrm{U} / \mathrm{kg}$ or $0.2 \mathrm{U} / \mathrm{kg}$ if blood glucose level was $<300 \mathrm{mg} / \mathrm{dl}$ or $\geq 300 \mathrm{mg} / \mathrm{dl}$, respectively) followed by hourly adjustments of $0.1 \mathrm{U} / \mathrm{kg}$ until reaching a stable metabolic condition to be followed up every 4 hours (normohydration, $\mathrm{pH}$ $\geq 7.30$, bicarbonate $\geq 15 \mathrm{mEq} / \mathrm{L}$ and blood glucose level $\leq 250 \mathrm{mg} / \mathrm{dl}$ ). Laboratory parameters (urea, creatinine, acid base status [ABS], electrolyte panel, blood glucose, blood count) were determined upon admission and then at 2, 6, 12 and 24 hours. Besides, blood glucose level, diabetic urine and ketonuria were tested on an hourly basis with test strips and, if blood glucose level was $\leq 250 \mathrm{mg} / \mathrm{dl}$, a blood test was immediately done to check whether the patient was metabolically stable to be moved to follow up at 4-hour intervals. For the purpose of this study, when the patient was followed up every 4 hours, it meant the critical period of this complication had been overcome, and such moment was considered as "recovery from DKA".

The following data was collected: age, sex, whether it was the first manifestation of the disease, accompanying symptoms (fever, vomiting, diarrhea, abdominal pain), correct or incorrect administration of insulin. Upon admission at the hospital, prior to starting treatment, clinical data (weight, heart rate, respiratory rate, neurological status measured by the Glasgow Coma Score, ${ }^{8}$ urinary output and mean blood pressure) and laboratory parameters (blood count, urea, creatinine, blood glucose, sodium, potassium, chloride, plasma $\mathrm{pH}$, plasma bicarbonate, carbon dioxide and presence of ketonuria and glycosuria) were recorded. Then, the following parameters were assessed until the patient recovered from DKA: time elapsed until reaching a stable condition, volume of administered fluid $\left(\mathrm{ml} / \mathrm{m}^{2}\right)$, units of insulin administered (IU/ kg) and use of bicarbonate. Besides, patients who required intensive care, and cases of cerebral edema and/or death were recorded.

\section{Definitions}

DKA: metabolic decompensation in type 1 diabetes mellitus characterized by blood glucose level $>200 \mathrm{mg} / \mathrm{dl}$, MA ( $\mathrm{pH}<7.30$ and/ or bicarbonate $<15 \mathrm{mEq} / \mathrm{L}$ ), glycosuria and ketonuria. $^{3}$

Based on laboratory parameters upon admission, the following was defined:

- MA: plasma bicarbonate concentration $<22 \mathrm{mEq} / \mathrm{L}$ with or without $\mathrm{pH}<7.35 .{ }^{6,9}$ 
- AG: difference between sodium and the sum of chloride with bicarbonate (normal value: $12 \pm 2 \mathrm{mEq} / \mathrm{L}$ ). Its value was adjusted based on plasma $\mathrm{pH}$ (decrease of $1 \mathrm{mEq} / \mathrm{L}$ of $\mathrm{AG}$ per each decrease of 0.1 of blood $\mathrm{pH}$ ) and the first available value of serum albumin (decrease of $2 \mathrm{mEq} / \mathrm{L}$ of AG per each decrease of $1 \mathrm{~g} / \mathrm{dl}$ of plasma albumin). ${ }^{7}$

- Hyperchloremia: plasma chloride $>75 \%$ of natremia. ${ }^{4,6}$

- MA with high AG: MA with an AG $>14 \mathrm{mEq} / \mathrm{L}$ with normal plasma $\mathrm{pH}$ (7.357.45) and albumin (4-5 g/ dl)., ${ }^{7,9}$

- MA with a hyperchloremic component: MA with an increased AG together with hyperchloremia..$^{4,6}$

- Osmolarity: it was estimated based on the following formula: plasma $\mathrm{Na}^{+} \times 2+$ blood glucose $(\mathrm{mg} / \mathrm{dl}) / 18+\operatorname{uremia}(\mathrm{mg} / \mathrm{dl}) / 6$. A value of 275-290 mosm/L was considered normal. ${ }^{7}$

Cerebral edema: deterioration of the level of consciousness accompanied by one or more signs of intracranial hypertension (arterial hypertension, bradycardia, alterations of the respiratory pattern, pupillary alterations, strabismus, blurry vision, posture of decortication or decerebration, respiratory arrest, radiologic or post-mortem evidence of moderate or severe cerebral edema). ${ }^{2,10}$

Degree of dehydration: it was assessed in terms of weight loss percentage, calculated as the difference between the weight at discharge and the weight recorded before the start of treatment. ${ }^{11,12}$

Decreased urinary output was defined as a low urine excretion (either perceived by the patient or reported by the patient's parents) within a few hours prior to hospitalization. ${ }^{12}$

Ethical considerations: The study was approved by the Ethics Committee and the Research Committee of our hospital. The informed consent of parents or guardians was obtained, as well as the patients' assent if they were older than 12 years old.

\section{Statistical analysis}

Recovery time from DKA was considered as the outcome measure, and the presence of MA with a hyperchloremic component in the laboratory test at admission was the predictive outcome measure. In our country, the minimum time to reach the outcome measure is 8 hours, ${ }^{1}$ but other authors have reported a faster decrease in blood glucose levels $\leq 250 \mathrm{mg} / \mathrm{dl}$ (5.8 hours), i.e., approximately 2 hours faster. ${ }^{13}$ Taking this information into account, it is speculated that, in patients with hyperchloremia, the objective to reduce recovery time by 2 hours could be achieved. To evidence this difference in the treatment, a sample size of 16 patients per group (power of $80 \%, 95 \%$ confidence interval) was estimated. In order to analyze the data, patients were divided into two groups: (1) MA with a hyperchloremic component and (2) MA with high AG only.

Clinical and demographic characteristics as well as laboratory and clinical course parameters were analyzed descriptively. Quantitative outcome measures had a non-parametric distribution (Shapiro-Wilk's test), so they were expressed as a median (range) and compared with the Wilcoxon test. Categorical outcome measures were expressed as the rate of presentation and percentage, and compared with the $\chi^{2}$ test or with the Fisher's exact test, as appropriate. The Statistix software, version 7 (IBM version; Analytical Software, Tallahassee, FL) was used, and a $p$ value $<0.05$ (two-tailed) was considered as statistically significant.

\section{RESULTS}

During the recruitment period, 52 patients with DKA were hospitalized in our institution. Twelve of them were excluded: 7 , because they had received treatment prior to the baseline lab test; 4 , because they have been referred from another hospital, and 1 because of multiple organ failure. Therefore, the study sample consisted of 40 patients ( 23 females) with a median age of 14.5 years (2.4-18); in 5 cases this was the first manifestation of the disease.

A hyperchloremic component in MA was observed at the onset in 22 patients (prevalence of $55 \%$ ), and MA due to high AG only was found in 18 cases. Both groups of patients were similar as far as demographic characteristics, and laboratory and clinical course parameters, except regarding the prevalence of abdominal pain, which was significantly higher in patients without hyperchloremia (Tables 1-3). It is worth pointing out that the presence of hyperchloremia at admission was not associated with a better hydration status (the median weight loss percentage both in patients with a hyperchloremic component as in patients with an exclusive high AG was $4.9 \%, \mathrm{p}=0,81$ ) nor with a better treatment response. In fact, patients with a 
e368 / Arch Argent Pediatr 2018;116(3):e365-e370 / Original article

TABLE 1. Comparison of demographic and clinical outcome measures at admission among DKA patients: MA with a hyperchloremic component and MA due to high anion gap only

\begin{tabular}{lccc}
\hline Outcome measure & $\begin{array}{c}\text { MA with a hyperchloremic } \\
\text { component (n= 22) }\end{array}$ & $\begin{array}{c}\text { MA with high AG only } \\
\text { (n= 18) }\end{array}$ & P value \\
\hline Age (years old) & $15.5(5.5-18)$ & $13.25(2.4-18)$ & 0.45 \\
Sex (F/M) & $13 / 9$ & $10 / 8$ & 0.82 \\
Baseline body weight (kg) & $44(15.5-67)$ & $42(12-64)$ & 0.79 \\
First manifestation (yes/no) & $2 / 20$ & $3 / 15$ & 0.65 \\
Fever & 3 & 2 & 1 \\
Vomiting & 18 & 12 & 0.46 \\
Diarrhea & 2 & 0 & 0.49 \\
Abdominal pain & 13 & 17 & 0.02 \\
Decreased urinary output & 5 & 4 & 0.68 \\
Mean blood pressure (mmHg) & $90(85-95)$ & $85(70-95)$ & 0.58 \\
Glasgow coma score & $15(13-15)$ & $15(14-15)$ & 0.56 \\
Correct administration of insulin & $7^{*}$ & $3 \#$ & 0.45 \\
Heart rate (bpm) & $120(88-140)$ & $120(88-150)$ & 0.69 \\
Respiratory rate (rpm) & $22(14-30)$ & $24(16-45)$ & 0.6 \\
\hline
\end{tabular}

MA: metabolic acidosis; AG: anion gap; F/M: female/male; bpm: beats per minute; rpm: respirations per minute; ${ }^{*} \mathrm{n}$ total= 20 and \# $\mathrm{n}$ total $=15$ (because patients who had their first clinical manifestation of diabetes were excluded).

TABLE 2. Comparison of laboratory parameters among DKA patients: MA with a hyperchloremic component and MA due to high anion gap only

\begin{tabular}{lccc}
\hline Laboratory parameters & $\begin{array}{c}\text { MA with a hyperchloremic } \\
\text { component }(\mathbf{n}=\mathbf{2 2})\end{array}$ & $\begin{array}{c}\text { MA with high AG only } \\
\mathbf{( n = 1 8 )}\end{array}$ & P value \\
\hline $\mathrm{pH}$ & $7.19(6.94-7.29)$ & $7.15(7.06-7.28)$ & 1 \\
Carbon dioxide (mmHg) & $23(13-37)$ & $26(18-40)$ & 0.09 \\
Bicarbonate (mEq/L) & $9(4.1-14.3)$ & $10(5.8-14)$ & 0.22 \\
Sodium (mEq/L) & $140.5(133-149)$ & $143(135-156)$ & 0.08 \\
Potassium (mEq/L) & $4.4(2.8-6.4)$ & $4.5(3.2-6.8)$ & 0.53 \\
Chloride (mEq/L) & $111(106-118)$ & $105(97-113)$ & 0.0001 \\
Blood glucose level (mg/dl) & $435(214-1077)$ & $431.5(205-847)$ & 0.85 \\
Creatinine (mg/dl) & $0.5(0.4-0.9)$ & $0.69(0.5-0.8)$ & 0.46 \\
Urea $(\mathrm{mg} / \mathrm{dl})$ & $32(18.8-58)$ & $41(20-114)$ & 0.16 \\
WBC count $(\mathrm{mm})$ & $13800(6200-36500)$ & $13500(7500-23500)$ & 0.97 \\
Hematocrit $(\%)$ & $45(38.7-50.8)$ & $44(34-49)$ & 0.25 \\
\hline
\end{tabular}

MA: metabolic acidosis; AG: anion gap.

TABLE 3. Comparison of treatments administered and clinical course among DKA patients: MA with a hyperchloremic component and $M A$ due to high anion gap only

\begin{tabular}{lccc}
\hline Outcome measure & $\begin{array}{c}\text { MA with a hyperchloremic } \\
\text { component }(\mathbf{n}=\mathbf{2 2})\end{array}$ & $\begin{array}{c}\text { MA with high AG only } \\
(\mathbf{n}=\mathbf{1 8})\end{array}$ & P value \\
\hline Weight loss $(\%)$ & $4.9(3.3-8.9)$ & $4.9(3-10.9)$ & 0.81 \\
Total volume of infused fluid $\left(\mathrm{ml} / \mathrm{m}^{2}\right)$ & $3125(1400-5300)$ & $3110(1500-4500)$ & 0.49 \\
Total insuline administered $(\mathrm{IU} / \mathrm{kg})$ & $0.95(0.3-3.4)$ & $1(0.5-1.9)$ & 0.72 \\
Use of sodium bicarbonate & 3 & 1 & 0.61 \\
Recovery time from DKA (hours) & $9.5(3.3-24)$ & $11(5.75-20)$ & 0.64 \\
Cerebral edema & 0 & 0 & 0 \\
Requirement of intensive care support & 0 & 0 & 0 \\
Death & 0 & 0 & 0 \\
\hline
\end{tabular}

MA: metabolic acidosis; AG: anion gap; DKA: diabetic ketoacidosis. 
hyperchloremic component reached the phase of recovery after 9.5 hours while the others did it at 11 hours $(p=0.64)$, with similar requirements of intravenous fluids and subcutaneous insulin (Table 3).

None of the patients developed cerebral edema nor required to be transferred to the intensive care unit. No deaths were registered either.

\section{DISCUSSION}

During electrolyte replacement in DKA a large amount of anion chloride is used, and consequently the development of hyperchloremia during treatment is a common finding in these patients (58-94\%). ${ }^{14-18}$ However, there is scarce information regarding the presence of hyperchloremia at the time of admission. ${ }^{14,15}$ In this study, 40 children admitted with DKA were assessed during 2,5 years. The median age of the studied group was 14.5 years and there was a slight predominance of female patients. It should be mentioned that it was the first manifestation of the disease only in $5(12.5 \%)$ of the cases, a lower rate compared to that reported in other studies. ${ }^{1}$ The reason could be that a great number of patients are followed up at the Department of Nutrition and Diabetes in our Hospital, and, in general, they are also seen in our institution if complications arise.

The analysis of the metabolic pattern when our patients were admitted to the hospital, before receiving any kind of treatment, revealed a prevalence of hyperchloremia of $55 \%$, which is markedly elevated compared to findings reported in previous studies. Mrozik et al., in a series of 59 children with DKA, did not find hyperchloremia at the onset of the clinical condition; however, it should be taken into account that they considered hyperchloremic only those children who did not have an increased AG (AG > 16) ${ }^{14}$ On the contrary, Taylor et al., who defined hyperchloremia as plasma chloride / sodium ratio $>0.79$, reported a prevalence of $6 \%$ in a series of 18 children. ${ }^{15} \mathrm{~A}$ likely cause of the differences of prevalence found between the present study and those mentioned before could be the definition used for hyperchloremia, which, in our case was the most widely accepted in the bibliography (plasma chloride/ sodium ratio > 0.75). ${ }^{4,6}$ If Taylor's definition had been used, the prevalence of hyperchloremia in our study would have decreased by half, which is still higher than that of other studies.
As mentioned before, it would be expected that patients with a hyperchloremic component would be better hydrated and, consequently, solve their metabolic disorder more quickly. However, as far as we know, no studies have looked into this hypothesis in the clinical setting. In our series, no differences were shown regarding the hydration status as revealed by weight loss percentage at the time of admission. According to this finding, no differences were found either in certain laboratory parameters that can be modified by extracellular fluid volume, such as hematocrit and urea levels (Table 2), nor in the clinical parameters associated with a previously higher weight loss percentage (Table 1). As expected, considering that there were no differences in the hydration status, the response to treatment measured in terms of the recovery time from DKA was also comparable between both groups (Table 3 ).

A limitation that should be mentioned is that prior to admission, fluid losses (vomiting, diarrhea, hyperthermia) were evaluated from a qualitative standpoint though their magnitude was unknown. Beyond this, it seems difficult to conduct a study to accurately assess these outcome measures, since these events occurred prior to admission. Additionally, our patients' hydration status was evaluated according to weight loss percentage, which was a quantifiable and objective measure. Likewise, even though the treatment guidelines point out that hourly checks should be performed in order to identify patients that have recovered from DKA, it is not possible to accurately rule out small shifts in checkup times of the patients'status.

As a strength of this study, it should be noted that data collection was performed in a prospective fashion and that all patients were treated under the same treatment schedule.

\section{CONCLUSION}

Among our patients with DKA, the prevalence of MA with a hyperchloremic component was 55\% and was not associated with a better hydration status nor with a faster recovery from the metabolic decompensation.

\section{REFERENCES}

1. Ferraro M, Ozuna B, Ramos O, et al. Estudio multicéntrico de cetoacidosis diabética en servicios pediátricos de Argentina. Rev Soc Argent Diabetes 2009;43:127-36.

2. Glaser N, Barnett P, McCaslin I, et al. Risk factors for cerebral edema in children with diabetic ketoacidosis. The Pediatric Emergency Medicine Collaborative Research Committee of the American Academy of Pediatrics. NEngl J Med 2001;344(4):264-9. 
3. Ramos O, Ferraro M, Barbeito S. Cetoacidosis diabética. En Voyer L, ed. Criterios de diagnóstico y tratamiento en Pediatría. $2^{\text {nd }}$ ed. Buenos Aires: Journal; 2006.Pages.95-100.

4. Repetto HA. Desequilibrios hidroelectrolíticos y ácidobásicos en la descompensación de la diabetes. Arch Argent Pediatr 2000;98(1):47-50.

5. Adrogué HJ, Eknoyan G, Suki WK. Diabetic ketoacidosis: role of the kidney in the acid-base homeostasis re-evaluated. Kidney Int 1984;25(4):591-8.

6. Massó D, Repetto HA. Fisiología y fisiopatología de la homeostasis del estadoácidobase. In: Nefrología Pediátrica. 2nd ed. Buenos Aires: FUNDASAP; 2008.Pages.355-80.

7. Rose B, Post T. Acidosis Metabólica. In Rose BD, Post TW, eds. Trastornos de los electrolitos y del equilibrio ácido base. 5th ed. Boston: Marban; 2002.Pages.78-646.

8. Moore L, Lavoie A, Camden S, et al. Statistical Validation of the Glasgow Coma Score. J Trauma 2006;60(6):1238-44.

9. Tejedor A, Caramelo C. Acidosis metabólica. In Ayus JC, Caramelo C, eds. Agua, electrolitos y equilibrio ácidobase: aprendizaje mediante casos clínicos. Madrid: Panamericana; 2006.Pages188-222.

10. Bohn D. Understanding the pathophysiology of cerebral edema in diabetic ketoacidosis: another brick in the wall? Pediatr Crit Care Med 2010;11(3):421-3.

11. Freedman SB, Vandermeer B, Milne A, et al. Diagnosing clinically significant dehydration in children with acute gastroenteritis using noninvasive methods: a meta-analysis. J Pediatr 2015;166(4):908-916.e1-6.

12. PringleK, ShahSP, Umulisa I, et al. Comparing the accuracy of the three popular clinical dehydration scales in children with diarrhea. Int J Emerg Med 2011;4:58.

13. Ballesteros Calderón AL, Meneses Muñoz AP, Ríos Patiño D, et al. Características epidemiológicas y clínicas y hallazgos de laboratorio de los niños menores de 15 años con cetoacidosis diabética atendidos en el Hospital UniversitarioSan Vicente Fundación en Medellín. IATREIA 2013;26(3):278-290.

14. Mrozik LT, Yung M. Hyperchloraemic metabolic acidosis slows recovery in children with diabetic ketoacidosis: a retrospective audit. Aust Crit Care 2009;22(4):172-7.

15. Taylor D, Durward A, Tibby S, et al. The influence of hyperchloraemia on acid base interpretation in diabetic ketoacidosis. Intensive Care Med 2006;32(2):295-301.

16. Basnet S, Venepalli PK, Andoh J, et al. Effect of normal saline and half normal saline on serum electrolytes during recovery phase of diabetic ketoacidosis. J Intensive Care Med 2014;29(1):38-42.

17. Orlowsky JP, Cramer CL, Fiallos MR. Diabetic Ketocidosis in the pediatric ICU. Pediatr Clin North Am 2008;55(3):577-87.

18. Ferreira JP, Hamui M, Torrens $M$, et al. The Influence of Chloride for the Interpretation of Plasma Bicarbonate During the Treatment of Diabetic Ketoacidosis. Pediatr Emerg Care 2017 [Epub ahead of print]. 